\title{
Julián del Casal y el modernismo
}

T A obra de Casal, recogida en tres libros, Hojas al Viento, Busbos y Limas y Nieve, apareció con regularidad en las revistas cubanas de la época, principalmente El Fígaro y La Habana Elegante. El Figaro se encontraba completa en la Biblioteca Nacional de La Habana. La Habana Elegante estaba repartida entre las bibliotecas del Centro Gallego, la Sociedad de Amigos del Pais y la colección particular de Julio Hernández Miyares. La colección completa de la familia Hernández Miyares fue do. nada hace unos pocos años a la Sociedad Económica. Algunas de sus "japonerías" y sus cuadros, que habían pasado por herencia a ser posesión del hijo de Enrique Hernández Miyares, fueron confiscados cuando la familia salió de Cuba, en r96r. No parece posible encontrar colecciones de La Habana Elegante en otros países. No debe haber ejemplares en la Argentina porque no la citan los críticos argentinos y no los hay en los Estados Unidos,' según la Biblioteca del Congreso. En la Biblioteca Nacional de México se encuentran ejemplares de La Habana Literaria, pero ninguno de La Habana Elegante. Es decir ni en los extremos ni en el centro del continente hay la posibilidad de cotejar fechas $y$ datos, ni de consultar la prosa de Casal, tan vital para el conocimiento de su vida y de su arte.

Posiblemente el error más grave a que ha dado base el ignorar la información bibliográfica se refiera al muy comentado problema de las precedencias. Monner Sans, basado en los estudios de Cabrera y Duplessis, toma el soneto "Mis amores" como prueba de la anticipación de Darío en el uso de los brillantes tópicos del modernismo. El soneto sería prueba concluyente de que Casal no se adelantó a Dario en el uso de los temas y figuras más comunes del modernismo, según Monner Sans:

1 V. John E. Englekirk, "La literatura y la revista literaria en Hispanoamérica", Revista Iberoamericana, números 51 a 55 . 
b) Mis anores si interesaría, debido al vocabulario y a la filiación parnasiana que se denuncian en versos como los siguientes:

Amo el bronce, el cristal, las porcelanas,

...las flébiles baladas alemanas...

... del pebetero la fragante esencia

y el lecho de marfil, sándalo y oro. ${ }^{2}$

Cree Monner, de acuerdo con sus fuentes, que este soneto es de 1890. Pero el soneto apareció en La Habana Elegante el 18 de julio de 1886 ; es por lo tanto anterior a $A z a l .$. que empieza a publicarse en diciembre de 1886 . Lo que hace Casal en 1890 , cuando publica el soneto en $E l . F ;$. garo, es simplemente cambiar los tercetos, sustituyéndolos por una enu. meración de imágenes que es, a su vez, mejor anticipo del oropel modernista que las composiciones de $\mathrm{Azul}$. Este es el soneto original, que ahora se reproduce por primera vez:

Amo el bronce, el cristal, las porcelanas

las vidrieras de múltiples colores, los tapices pintados de oro y flores $y$ las brillantes lunas venecianas.

Amo también las bellas castellanas, la canción de los viejos trovadores, los árabes corceles voladores, las flébiles baladas alemanas.

Pero amo mucho más, Rosa hechicera, que escuchas mis cantares amorosos, contemplar con miradas devorantes,

el oro de tu larga cabellera, el rojo de tus labios temblorosos, y el negro de tus ojos centelleantes.

2 José Maria Monner Sans, Julián del Casal y el modernismo bispanoamesicano (México, 1952), p. 105. (Subsiguientes citas de esta obra se hacen indicando solamente el número de página.) V. también Gustavo Duplessis, Julián del Casal (Habana, 1945) y Mario Cabrera Saqui, Poesías completas de Julián del Casal (Habana, 1945). Esta última es la llamada edición oficial de la obra del poeta cubano. 
$\mathrm{L}_{\mathbf{a}}$ versión que aparece en Hojas al viento presenta distintos tercetos:

El rico piano de marfil sonoro, el sonido del cuerno en la espesura, del pebetero la fragante esencia,

y el lecho de marfil, sándalo $y$ oro, en que deja la virgen hermosura la ensangrentada flor de su inocencia.

Con toda claridad dice Monner que el Casal de 1886 emplea dos versos típicamente modernistas "amo el bronce, el cristal, las porcelanas", "y las flébiles baladas alemanas". Como vemos, si Casal ha escrito medio soneto modernista en 1886 , es el predecesor de Darío exactamente en dos años y cuatro meses. Y como "Caupolicán" es de 1888 , el crítico argentino basa en él sus teorías de las primacías de Rubén. Pero "Cau. policán" es sugerente porque sitúa a Darío en contacto directo con la Isla de Cuba.

Hay completo acuerdo en el "galicismo mental" de los modernistas pero se olvida que la geografía de la América española a fines del siglo XIX hacía de la ciudad de La Habana el punto lógico de impacto para las ideas europeas. No habia un canal de Panamá y las modas y manías de París desembarcaban en La Habana antes de seguir camino al sur. Nada menos que el perspicaz $D$. Marcelino reconoció el francesismo de la Isla, para él, desde luego, una característica atroz:

Hoy quizá, entre todas las literaturas de América, la menos española es la cubana.

En francés se piensa, en francés se siente, en francés se habla, $y$ ni siquiera la vecindad

de lós Estados Unidos basta para llevar los espiritus por otro camino y apartatlos de una superstición que, en algunos de los más discretos, toma visos de fetichismo. ${ }^{3}$

La selección le había sido enviada por un grupo oficial del que formaban parte Domingo del Monte y Manuel Serafín Pichardo, amigos

3 Marcelino Menéndez y Pelayo, Antologia de Poelas Hispano Americanos (Madrid, 1893), II p. lix. 
de Casal. Como D. Marcelino no podía ignorar los famosos artículos de Valera, su testimonio es una corrección indirecta y un ataque público a una tendencia que amenazaba convertirse en moda de todo un continente. Para cualquier cubano de su tiempo, y para cualquier hispanoamericano cnterado, las palabras de don Marcelino se referían a Casal, también a su amigo el Conde Kostia (Aniceto Valdivia), y a todo el grupo de La Habana Elegante.

La Habana Elegante era una revista encantadora y fina, imptesa en lujoso papel satinado. Había sido fundada unos años después de la Paz del Zanjón, por unos cuantos jóvenes amigos del deporte y de las letras, capitaneados por Casimiro del Monte. Más tarde, bajo la dirección de Ignacio Sarachaga, se hizo famosa por sus crónicas mundanas y sus caricaturas. En su tercera etapa llegó a ser un periódico ilustrado de gran fama en el mundo de habla española, y duró hasta la Guerra de Independencia, cuando sus redactores principales tuvieron que emigrar o marcharse "a la manigua". La redacción no era solamente un parnasillo sino también un campamento revolucionario según testimonios contemporáneos. Su último director, Enrique Hernández Miyares, ha sido tan injustamente olvidado como la revista. La única edición que se ha hecho de sus obras fue preparada por José Manuel Carbonell para la Academia de Artes y Letras de La Habana en r9r6. A Hernández Miyares se le debe el precioso soneto "La más fermosa", recogido por José Maria Chacón y Calvo en Las cien mejores poesias cubantas:

Que siga el caballero su camino, agravios desfaciendo con su lanza, todo noble tesón, al cabo aicanza fijar las justas leyes del destino.

Cálate el roto yelmo de Mambrino y en tu rocin glorioso altivo avanza, desoye al refranero Sancho Panza, y en tu brazo confía y en tu sino.

No temas la esquivez de la fortuna; si el caballero de la Blanca Luna medir sus armas con las tuyas osa, 
y te derriba por contraria suerte, de Dulcinea en ansias de la muerte, di que siempre serás la más fermosa!

A este Enrique dedicó Darío su "Caupolicán". Este soneto, según la antología recogida en los Anales de la Universidad de Chile, apareció en La Epoca el ix de noviembre de I 888 dedicado a Hernández Miyares. Según Saavedra Molina la dedicatoria no aparece hasta 1890.4 Que haya sido dedicado a un cubano en 1888 o en 1890 carece de importancia para el caso Casal aunque sí lo sea para establecer contactos entre Dario y otros escritores de su tiempo. Demuestra, sí, que Dario conocia muy bien a La Habana Elegante y que hay que añadir esta revista a la lista de periódicos que contribuyeron a la difusión del modernismo. El 3 I de julio de $\mathrm{r} 887$ el propio Hernández había comentado el primer artículo publicado sobre Darío, el de Pedro Balmaceda Toro, aunque su admiración fuese un tanto reservada:

En cuanto a las otras citas no he de reproducirlas; el abuso y mal uso de los diptongos es la invasión churrigueresca en el grandioso templo levantado a las musas por los inmortales poetas del Sud, que nos han dejado por herencia un nombre entre tradiciones glo. riosas, y sigue siendo el golpe de cincel antiartístico que descom. pone las estatuillas de terra-cotta que hoy presentan en los museos de papel-periódicos-los llorosos acompañantes al lugar de descanso de la poesía: diosa que muere llorada por Macauly y a despecho de los versos del protestante Gustavo Adolfo. ${ }^{5}$

El II de diciembre del mismo año aparece en la portada de la revista el "Caso cierto", luego recogido como "Caso". En octubre de I889 sale "Claro de luna" que tuvo que resucitar Regino E. Boti treinta años más tarde. En medio de las amnesias de Darío hay pruebas suficientes de que estaba en contacto con los cubanos. Además La Habana Ele. gante era una revista de tantas campanillas intelectuales como La Epoca y su francesismo mucho más directo. De ahí que se pueda argüiri con

4 Anales de la Universidad de Chile (1941) p. 278, incluye la dedicatoria a Hernández Miyares. Julio Saavedra Molina y Edwin K. Mapes, Obras escogidas de Rubén Dario publicadas en Cbile, (Santiago, 1939) p. 359, explican, en una nota, que en La Epoca este soneto se titula "El Toqui" y no lleva dedicatoria. A su vez la nota de $A z z l$... 1890, confunde a Caupolicán con Leocato.

.5 V. Esperanza Figuetoa, "Julián del Casal y Rubén Dario", Revista Bimestre Cubana, L2 (1942). Reproducido en La Prensa, N. Y. (28 jul.-4 ag. 1943). 
bastante lógica que hay puntos de contacto entre la gestación de $A z u l \ldots$ y la revista cubana aunque nadie los haya establecido concretamente. Es increible que los tesoros de La Habana Elegante hayan permanecido olvidados durante más de medio siglo. La revista era perfectamente asequible cuando Monner Sans publicó su libro sobre Casal y en ella hubiera podido rectificar o comprobar sus datos, o preparar una verdadera edición crítica. Hoy tenemos que referirnos a ella a través del recuerdo, y sin un cono. cimiento extenso de La Habana Elegante - y de otras revistas cubanas como La Habanta Literaria- la historia del modernismo no está com. pleta.

Sin consulta directa con las publicaciones de Cuba los trabajos sobre el modernismo tienen que hacerse con datos de segunda mano. La parte más débil del bello trabajo de Monner sobre Casal es la de las precedencias. Es cierto que la crítica española del siglo XIX se hizo muy puntillosa en lo de establecer precedencias, mortificada por la penetración francesa, pero hoy es dificil considerar a Garcilaso o a Góngora, que acostumbra. ban a aprovecharse de versos enteros de Petrarca o de Ovidio, como poetas plagiarios. ${ }^{\circ}$ Las ideas de Monner sobre originalidad y precedencias son exactas y explícitas. Está dispuesto "a poner orden en este pleito y valo. rar las pruebas ofrecidas" y to hace redondamente sin dejar de llamar presuntuoso a Geada porque se atrevió hasta a considerar a Casal pre. cursor de Dario, aunque haya sido "hasta cierto punto":

Recuérdese, en efecto, que la primera edición de $A z u l .$. data de 1888 y la segunda, con importantes adiciones, de 1890 . Y tecuérdese que los libros de Casal son, respectivamente, de $1890,92, y$ 93. ¿En qué piezas basa, pues, Geada su presunción? (ro4)

Procede a desmenuzar, con los datos que le proporcionan unos pocos libros cubanos, los poemas que Geada aduce como ejemplos: "Lazos de muerte", "Mis amores", "El anhelo de una rosa", "Desolación", "Neurosis" y "Nihilismo". Ya hemos notado que Monner aceptaría "Mis amores" como una prueba parcial del modernismo de Casal, sólo que hay una diferencia de cuatro años entre la fecha en que se publicó y la que Monner conoce. En cuanto a "Desolación" esto es lo que opina:

d) "Desolación", que sí es de 1887 , tampoco constituye tes-

6 Para un estudio modelo de precedencias y originalidad, consúltese Antonio Vilanova, Las fuentes y los temas del Polifemo de Góngora, (Madrid, 1957). Se trata de un trabajo exhaustivo donde sa prueban anchamente las ideas de Curtius respecto al tópico y de Menéndez Pidal en cuanto a la tradición literaria. 
timonio decisivo de la antecedencia de Casal, porque se trata de su soneto típicamente romántico abrochado con muy gastada síntesis (106).

Hay muchas notas interesantes en "Desolación". En primer término rompe el silencio de un año, porque entre el octubre del 86 y el octubre del 87 en que aparece, Casal no ha publicado ni una sola poesia, sólo una crónica y las traducciones de Baudelaire. "Desolación" no es un poema modernista si consideramos al modernismo como mero desfile de espléndidos azules. Pero si es también imagen y sensación, el símbolo de Poe y el ave de González Martínez entonces tendremos que considerar este soneto como un ejemplo del modernismo: "En la torre agrietada y ama. rilla/el pajaro fatídico aletea". El choque plástico del ave negra contra el muro amarillo se afianza en la alusión, porque no sabemos si se re. fiere al buho sabio o al murciélago ominoso. El lenguaje se ciñe a la representación, un verso casi vertical para la torre inmóvil y el vibrar de las esdrújulas para el pájaro. Pero hay más: "Ningún monje sombrio, solitario/arrebujado en su capucha oscura". Las aliteraciones, las enes, emes, oes, del primer verso y la sucesión de u en el segundo, la sensa. ción de frío en "artebujado" que se refuerza en los adjetivos usados con el valor de sinestesia temperamental con que se repiten en toda la poesía de Casal, sombrio, solitario, oscuro. En "Desolación" se anticipa la técnica casaliana que tiene más de común con la poesia contemporánea que con la gracia versallesca de Darío. En cuanto a "Neurosis":

e) "Neurosis", desarrollada en sextina y cuya factura parangoné con la de "La duquesa Job"... hubiera podido establecer la prelación de Casal respecto a ciertos preciosismos rubenianos si fuera indubitablemente del $87 . \ldots$ su elocución se aproxima... a la del soneto "De invierno"... (106).

Es cierto que la composición es de 1893 pero nosotros no encontramos ninguna relación entre "Noemí", la pálida pecadora y la Carolina de Darío, de rima un tanto ripiosa, que "descansa en el sillón,/envuelta con el abrigo de marta cibelina/y no lejos del fuego que brilla en el salón". El tópico pudiera ser de Nájera pero aparece con más elegancia en los Versos sencillos:

Pálida, en su canapé

de seda tórtola y roja, 
Eva, callada, deshoja, una violeta en el te (XVI).

Es fácil notar que Martí está hablando del eterno femenino y que ésta es también la preocupación de Casal. En cambio las composiciones de Dario y Nájera son más simples, más periféricas, como ya veremos al ocuparnos de ellas. Nótese también que éstos se circunscriben al ambiente de las damas galantes mientras que en Martí y en Casal hay alusiones bíblicas a la perdición del hombre o a su vulnerabilidad frente a la mujer, Eva y Noemí. Es cietto que hay una nota rubendarista en "Neurosis", pero es la misma que aparece luego en Prosas profanas - libro publicado unos años después de la muerte de Casal $\longrightarrow$ porque Noemi es el anticipo de Eulalia, solamente que con más empaque universal. En cuanto a "Lazos de muerte", ésta es la opinión de Monner Sans:

a) "Lazos de muerte" - cuya fecha exacta no da Duplessis (II) - carece de interés porque sus redondillas conservan inconfundible dejo romántico. Ahí va la muestra:

$$
\begin{aligned}
& \text { En mi pálida poesía } \\
& \text { no encontrarás mi aflicción. } \\
& \text { ¡Yo llevo en el corazón } \\
& \text { oculta la pena mía! (IO5) }
\end{aligned}
$$

Esta composición se publicó el 28 de enero de 1886 en El Figaro bajo el título "Lazos de amor". Los críticos que se refieren a la nota modernista lo hacen sin duda basados en los versos "fúlgida como el diamante,/ardiente como el deseo". Además otra vez notamos en esta com. posición -que es una de las primerisimas de Casal-la nota perenne del dolor oscuro e incierto, en el uso de los adjetivos sin luz y el contraste entre luz y sombra en "como/en la ola sombria/el fulgor de la centella". En todo caso para comparar a Darío y a Casal, sobre la base de esta com. posición, habría que hacerlo usando al Darío de Abrojos y no al de Prosas profanas. Continúa Monner analizando las composiciones de Casal que se han aducido como ejemplos pre-Darío:

c) En cuanto al "Anhelo de una rosa", más es residuo de avie. jada poesía que estremecimiento de la que entonces afloraba en las letras de América. Empieza así: 
Yo era la rosa que en el prado ameno, abri mi cáliz de encendida grana, donde vertió sus perlas la mañana, como en un cofre de perfumes lleno.

Y sépase, todavia, que parece errónea la fecha del 86 atribuida a esta composición, pues tanto Duplessis (II), como la edición oficial de 1945 (Poesias completas de Julián de Casal) corrigen a Geada y fijan el 88 (I06).

Las afirmaciones u omisiones de Duplessis y de Cabrera parecen un tanto extrañas. Es inexplicable que se les haya pasado por alto que la "Bibliografía de Julián del Casal" registra escuetamente:

(x886) El deseo de una rosa. (A Manuel de la Cruz) HE (Habana Elegante) 13 junio. En Hojas al Viento, p. 50, con el título $\mathrm{El}$ anbelo de una rosa ( $\mathrm{I888}$ ) Monólogo de una rosa mar. chita. En el album de la señorita Cristiana Granados, F (El Fígaro) zo de junio, en Hojas al Viento, p. 50, dedicado a Manuel de la Cruz y notables variantes.?

"El anhelo de una rosa" es una de las primeras composiciones de Casal, la séptima, para ser exactos, si no contamos las composiciones románticas de 1881. Lo cierto es que el poena está lleno de imágenes modernistas, como los cofres de perfumes, cristales y el inevitable lago azul:

Del lago azul en el cristal sereno vi mi corola retratarse ufana, como ante fina luna veneciana ve una hermosura su marmóreo seno.

El tópico es $\tan$ viejo que tendriamos que ir a buscarlo en la poesía latina, pero la nota profética es muy casaliana: "Teniendo que morir porque el destino/hizo que breve mi existencia fuera". Ia videncia se ha de repetir mucho en su poesía. El poeta no está hablando de una rosa sino de sí mismo y hay en la obra de Casal una nota simbólica que hemos ignorado persistentemente.

7 Esperanza Figueroa, "Bibliografía de Julián del Casal", Boletin de Biblio. grafia Cubana, II (1942) 33-38. 
También se ocupa Monner de "Nihilismo" para afirmar que "tiene importancia dentro de la producción del poeta por cerrar la elipse de su pesimismo" (107). Pero la composición se publicó en La Habana Lite. raria el $\mathrm{r}_{5}$ de junio de 1892 cuando las composiciones más pesimistas de Casal estaban todavía por escribir. En resumen, que lo escrito por Juan J. Geada en I93I tiene todavia hoy una vigencia dolorosa:

Pronto van a cumplirse cuarenta años de su muerte, y sin em. bargo a estas horas no existe una edición definitiva de sus obras; el día que se conozca su labor, no sólo de poeta sino de prosista, podrá hacerse un juicio serio y acabado.

...Además hay que computar las fechas de algunas poesías que fueron apareciendo en esas publicaciones y más tarde se insertaron en los tres tomos ya citados, sin atender a un orden cro. nológico. De esta falta de fechas procede el error en que caen muchos criticos acerca de la influencia de Dario sobre Casal. ${ }^{8}$

Además de los ejemplos citados por Geada hay otros versos de Casal que pueden usarse para establecer su procedencia. Ya embarcados en esta crítica de almanaque vale citar "A Olimpia" de agosto de 1886 :
estar en fiestas brillantes;
tener amorosas citas;
poder a las margaritas
dar el collar de diamantes

y en septiembre de 1886 , en una imitación de Coppée, "El anhelo del monarca":
Arden en los pebeteros
los perfumes orientales
que en azules espirales
cruzan los aires ligeros.

Si la imitación de Hugo, "A Olimpia", comienza con un verso sugestivo; "Ver una hermosa desnuda" que tratándose de un poeta pintor nos re. cuerda la "Olimpia" de Manet y su seguro conocimiento de los grandes

8 Juan J. Geada y Fernández, Selección de poesias de Julian del Casal, (Habana, 1941) p. li. 
escándalos de las exposiciones francesas, la imitación de Coppé es en. cantadora por la certeza de su técnica:

\author{
Ondean los pabellones \\ por el viento desplegados \\ en los muros elevados \\ de los fuertes torreones.
}

No puede negarse que Julián del Casal sabe visualizar sus cuadros y puede interpretarlos en versos precisos y simétricos:

$\begin{array}{ll}\text { ondean } & \text { pabellones } \\ \text { viento } & \text { desplegados } \\ \text { muros } & \text { elevados } \\ \text { fuertes } & \text { torreones }\end{array}$

En cuanto a los sonetos, el crítico argentino está muy en desacuerdo con los que prefieren a Casal, pero en cuestión de predilecciones poéticas no pueden reconocerse pronunciamientos definitivos. Como Darío escribió sonetos antes de 1890 , Monner niega que los de Casal sean superiores. También señala que Darío aplicó al soneto las innovaciones métricas. Pero las innovaciones por sí mismas no hacen a la poesía poesía y entre los sonetos de Dario hay mucho poema de circunstancia.9 Los sonetos de Casal tienen más contenido subjetivo. "Vespertino", de no. viembre de 1887 , es un soneto modernista cargado del típico simbolismo casaliano. "Salomé" es de 1890 , lo mismo que "Pax animae", "Mi ensueño", "A un amigo". Después escribió sonetos señeros que pueden contarse entre los mejores de la poesía española, pero que han sido olvidados en medio de la sorpresa provocada por la novedad de su poesía. La mayor parte de los críticos no han reparado en la técnica casaliana del soneto -a pesar de su predominancia numérica entre las composi. ciones de Casal- preocupados por la nota estridente que repetidamente

9 Más de un poeta se ha rebelado contra el soneto en general -aunque des. pués hayan terminado escribiendo sonetos-y algunos han expresado su falta de admiración por los sonetos de Darío. Dice Antonio Machado: "Va el soneto de lo escolástico a lo barroco. De Dante a Góngora, pasando por Ronsard. No es composición moderna, a pesar de Heredia. La emoción del soneto se ha perdido. Queda sólo el esqueleto, demasiado sólido y pesado para la forma lírica actual. Todavía se encuentran algunos buenos sonetos en los poetas portugueses. En España san bellísimos los de Manuel Machado. Rubén Darío no hizo ninguno digno de mención". En Obras completas de Manuel y Antonio Marbado (Ed. Plenitud, Madrid, 1962), p. 1220. 
resucitan en "El hijo espurio", al que nunca dejan de enarbolar como gallardete simbólico de un pesimismo inmotivado y efectista.

Hay indicaciones de que Casal trató de renovar el soneto. El ejem. plo se halla en un poemita de I886, "El puente", una imitación de Victor Hugo, que pudiera leerse como un soneto asonante. La innovación no tuvo éxito, posiblemente por ser demasiado hibrida para la exacta arquitectura del soneto español:

Una noche sombría y pavorosa que a lo infinito aterrador miraba, y a través de las lóbregas tinieblas de la celeste bóveda enlutada,

Ia faz de Dios resplandecer veía, exclamó, llena de ansiedad, mi alma, - ¿Por qué puente seguro y gigantesco podré subir a las regiones altas, para el triste mortal desconocidas, donde el gran Creador tiene su estancia? $Y$ una blanca visión respondió entonces;

con armoniosa voz nunca escuchada:

-Yo te haré un puente si subir deseas.

- ¿Cuál es tu nombre? - dije- La Plegaria.

Pero las innovaciones de Casal son más de manera que de técnica. Hacia diciembre de 1887 tenemos "Estatua de carne", de final formulista pero con cuatro estrofas que recuerdan las duquesas mexicanas $y$ nos abren el camino para saludar a las marquesas de Centroamérica:

Blanco traje de gasa vaporosa cubría los encantos de su cuerpo, tendido entre cojines perfumados sobre diván de rojo terciopelo.

Aureo collar, ornado de rubíes, circundaba las líneas de su cuello, y sus dedos ebúrneos deshojaban ramos fragantes de heliotropos frescos. 
Ostentaba en sus lánguidas pupilas, abiertas siempre a los hermosos sueños, la blancura opalina de la estrella y la azul transparencia de los cielos.

Largo abanico de rosadas plumas colgaba airoso de su talle esbelto, mientras el aura suave deshacia los blondos rizos de su fino pelo.

Aura suave no es un vestigio romántico sino una fórmula renacentista que luego ha de convertirse en la tormenta arrolladora del aire swave. Las precedencias en literatura son extraordinariamente elásticas - como lo demuestra esa misma aura suave que parece haberse escapado de un soneto de Herrera-, pero lo cierto es que no se puede probar que Darío se haya anticipado a Julián del Casal en el uso consciente de los grandes temas, términos y enfoques característicos del modernismo.

Lo que no puede negarse, porque es demasiado evidente, es que Casal resucitó los eneasilabos y el terceto monorrimo. Los eneasilabos no podian ser muy peregrinos para un cubano porque ya Heredia había traducido a Lamartine en versos de ritmo interno un tanto desusado, publi. cados en México en I838.10 También doña Gertrudis había usado eneasí. labos y otro cubano, mucho menos conocido, Ignacio Valdés Machuca, de quien dice Max Henriquez Ureña que fue "un imitador de Meléndez Valdés y de Arriaza". "1t A pesar de todo lo anterior se ha tratado de de. mostrar que Casal no fue el primer modernista que usara el eneasílabo libre aunque hasta ahora no se hayan podido aducir datos concretos. La crítica puede llegar muy lejos cuando trata de interpretar hechos en favor de sus favoritos como hace Monner cuando añade

A este respecto, en Dario pudo influir Casal con sus eneasílabos polirrítmicos de "Hortensia del Monte" - si Dario llegó a leerlos, pues no se recogieron en colección (ro9. Itálicas de la autora).

Para los conocedores del periodismo hispanoamericano y los enterados del extenso papel que jugó en el modernismo la comunicación epistolar, la conjetura anterior es enteramente ingenua porque ignora la difusión que

10 V. Poesias completas (Habana, 1941), II PP. 404.408.

ir Artologia cubana de las escuelas (Santiago de Cuba, 1929), p. 47. 
las revistas cubanas tenían en la América de habla española y el comprobado hecho de una relación Casal-Darío.

Casal demostró muchas veces un más certero instinto poético que Darío, por lo menos visto con los ojos sagaces de la poesía hermética. En r887 el poeta cubano estaba traduciendo a Baudelaire, que es el banderín y punto de partida de la poesía contemporánea mientras Dario no parece haberlo entendido, como podría deducirse de la nota a "Parodi" que trasmiten Saavedra y Mapes:

Comprendo que la poesia bañe de su divina luz el desnudo; admiro a Venus y a Leda; mas no comprendo a los poetas satiriacos, mitad hijos de Apolo, mitad hijos de Phallus. Tiene mucho de bello el impudor sagrado de las antiguas fiestas religiosas; el canto carnal del fauno, los saltos y gritos de ritual en las procesiones, porque en ellos se advierte el culto a la naturaleza. Pero ¿qué es eso de poner a nuestra poesía moderna a cantar la epopeya del burdel ?12

"La epopeya del burdel" parece un ataque tardío a las nuevas escuelas francesas y a las reminiscencias de Baudelaire. En ese párrafo, como en muchos otros, Dario tiene más de predicador victotiano que la percepción premonitiva de un poeta auténtico.

En la prosa es también Casal antetior a Dario. A fines de 1885 lo encontramos escribiendo sobre Manuel Reina (I856-1905) a quien lo mismo Onís que Borghini señalan como precursor. Según el primero es "el más culto e innovador de los poetas de su tiempo" y de acuerdo con el segundo "su premodernismo se revela en la delicadeza sensorial... " 13 "Tam. bién, a pesar de que Casal es un hombre enfermo que nos han pintado como un inadaptado sensiblero, es el poeta cubano el que está atento a los problemas sociales de su tiempo y menos dispuesto a decir frases lindas de los poderosos e influyentes. En 1888 ya estaba Casal escribiendo sus cró. nicas engagées sobre "la sociedad de la Habana" y esto le costó no solamente su puesto burocrático sino que también atrajo la excomunión sobre La Habana Elegante por haberse expresado con irreverencia sobre el Obispo de la ciudad. Un poco más adelante nos encontramos con otra faceta de su obra, poco conocida y mucho menos comprendida, cuando hacia 1890 comienza a inspirarse en los cuadros de Moreau, que no sola-

12 Obras escogidas...., p. 397.

123 .Federico de Onis, Antologia de la poesia española e bispano americana (Madrid, 1924), p. 22. Vittorio Borghini, Rubén Darío..., p. 111. Una breve cita de lo escrito por Casal scbre Manuel Reina se halla en Esperanza Figueroa, "Apuntes sobre Julián del Casal", Revista Iberoamericana (VII, 14, feb. 1944). 
mente era un "pintor literario" sino que se le conocia - en los círculos enterados- como experimentador atrevido. Atturo Symons, que dio a conocer a los simbolistas en Inglaterra, le llamó "visionario calculador" y aho. ra André Breton lo reclama como el primer surrealista. Moreau es tan des. conocido que vale la pena puntualizar que Casal no andaba muy desca. minado en su admiración por Moreau, porque Matisse fue uno de sus discípulos y también los pintores que en 1905 participaron en la exposi. ción fauvista, entre ellos Roualt. Después de $x 890$ la poesía de Casal $-y$ toda su obra- se condensa, concentrándose en sus temas característicos, la soledad y la muerte, cortada por ominosos silencios que sugieren épocas de enfermedades y convalescencias.

Como a Casal se le ha negado todo, también se le ha negado es. cuela. Cuando Monner Sans recuerda el pleito Lugones.Herrera Reissig señala en el uruguayo la influencia del àrgentino: "la del Lugones de Los crepuisculos del jardin (influencias) se trasvasa a algunos sonetos de Julio Herrera y Reissig" (II2). Pero nosotros vemos una nota casaliana en los sonetos de Herrera y creemos precisamente que los sonetos de Casal merecen mucha más atención de la recibida. Compárese "Un fraile" de Casal -que transcribimos primero- con "El cura" de Herrera y Reissig:

Descalzo, con oscuro sayal de lana sobre el lomo rollizo de su jumento, mendigando limosnas para el convento va el fraile franciscano por la mañana.

Tras él resuena el toque de la campana que a la misa convoca con dulce acento y se pierde en las nubes del firmamento, teñidas por la aurora de oro y de grana.

Opreso entre la diestra lleva el breviario, pende de su cintura tosco rosario, cestas de provisiones su mente forja,

y escucha que a lo largo del gran camino respondiendo al rebuzno de su pollino, silba el aire escondiéndose entre la alforja. 
II

Es el cura... Lo han visto las crestas silenciarias luchando de rodillas con todos los reveses, salvar en pleno invierno los riesgos montañeses o trasponer de noche las rutas solitarias.

De su mano propicia, que hace crecer las mieses, saltan como sortijas gracias involuntarias; y en su asno taumaturgo de indulgencias plenarias hasta el umbral del cielo lleva a sus feligreses...

El pasa del hisopo al zueco y la guadaña; él ordeña la pródiga ubre de su montaña para encender con oros el pobre altar de pino;

de sus sermones fluyen suspiros de albahaca: el único pecado que tiene es un sobrino... y su piedad humilde lame como una vaca.

Las correspondencias entre los dos sonetos son más bien de fondo y sentimiento, de escenario, que de forma. Pero no es este un caso aislado. Del mismo trío de los sonetos españoles de Casal es "Un torero", que termina con el lindo "donde quiebre el ocaso sus flechas de oro"; únase al cierre de "El despertar" de Herrera "como flechas perdidas de la noche en derrota". Y en uno de los sonetos de. Herrera, "El monasterio" encontramos una casi paráfrasis de la primera línea de "Un fraile": "Des. calzo, en dura arcilla, con el sayal escueto". Todo esto sin bucear mucho en los reflejos violeta y las palomas tímidas de Casal y las palomas violetas de Herrera y pasando por alto la predilección de Herrera por las sonorida. des esdrújulas, que muy bien pudo absorber del cubano.

El terceto monorrimo es la aportación más indiscutible de Casal a la técnica modernista, pero también se le ha negado la poca gloria que un hallazgo estructural podría añadir a su pericia poética. Así se expresa Monner:

Pero justo es decir que, alrededor del 90, esa temeridad de enristrar tres consonantes vecinas -aunque no en tercetos- debe reivindicarse para Rubén el magnífico, futuro maestro en viejas galas de trovar y ya paladin de audacias métricas y ya osado trans. 
gresor de toda norma. Eso sí: con lucidez en la audacia y tino alerta en la transgresión, porque alla en la hondura velaba, celoso, su avizor numen poético (75).

Dejando aparte el concepto tradicional de influencia e innovación que rige este tipo de crítica, notemos que Darío es el "magnífico", el "pala. dín", el "maestro", el posesor o el poseido del numen poético. Aquí hallamos mezclados juicios estéticos con detalles relativos a usos técnicos, conceptos básicamente distintos aunque no sean incompatibles. En este caso el entusiasmo estimativo ha cegado al crítico histórico porque no fue Darío el primer modernista que emparejó tal trinidad aunque Max Henriquez Ureña nos aclara que

...tiene su principal antecedente en Gonzalo de Berceo. El primer brote de esta reviviscencia lo encontramos en una especie de soneto libre que Rubén Darío escribió con motivo de la muerte de José Victoriano Lastarria (I888) en cuya novedosa distribución de con. sonancias aparecen tercetos monorrimos. ${ }^{\text {th }}$

No podemos olvidar que Casal había leído a Berceo con sus maestros jesuitas pero tenía también el ejemplo de Nájera. Este usa tres conso. nantes parejas en una de esas primeras composiciones que Casal parece haber conocido muy bien. Se trata de "Maria" que data de 1877 :

Hija del llanto y madre del consuelo, ella es la madre del linaje humano; ella la reina mística del cielo calma del hombre el padecer y el duelo, y con sublime amor y santo celo tiende hacia él su protectora mano. ${ }^{15}$

Fácil seria establecer la influencia de Nájera sobre Casal, y hablamos de influencia en el sentido de estructura y nociones heredadas, a la manera del tópico de Curtius. El contacto directo le puede haber llegado en España, a través de Icaza o puede haber sido anterior. Sabemos con certeza que después del viaje de Casal a España se escribian regular.

14 Breve bistoria del Modernismo (México, 1962), p. 14.

15 Manuel Gutiérrez Nájera, Poesias completas (Buenos Aires, 1946), I, p. 47. Todas las citas de Nájera de esta edición. Citas de Casal de la llamada edición oficial. 
mente. $\mathrm{Y}$ después del viaje se pueden determinar definidos puntos de contacto, con el "Nocturno II", que sabemos por fecha y nota al pie de composición que fue escrito en España y publicado en La Habana Elegante el 7 de febrero de 1889 . Este Nocturno recuerda " $\mathrm{La}$ noche de San Silvestre" que había escrito el poeta mexicano unos diez años antes. Los elementos son los mismos, el mismo poeta solitario e insomne, la misma lámpara que los alumbra:

Nájera.-Lámpara tenue débilmente alumbra las páginas del libro que no leo...

Casal._... duerme la tierra y solitario velo de mi lámpara ardiente a los fulgores.

Nájera.-Recortando medrosa en la penumbra las figuras exóticas que veo.

Casal.-Enjambre de quimeras fugitivas surgen de mi cerebro visionario.

Nájera.-Furtivo, vergonzante, mi pasado
se arropa en un rincón, entumecido,
y de lejos el rostro enmascarado,
acecha el porvenir, como bandido.
Casal.- Viendo de mi presente el campo yermo
recuerdo del pasado horas perdidas,
late mi pobre corazón enfermo
y se ensanchan sangrando sus heridas.

En cierta forma la huella de Nájera no dejó nunca a Casal. Aunque no se puedan establecer los detalles del intercambio de ideas entre los dos poetas sabemos de cierto que el mexicano le dedicó a su colega de Cuba su "Pax animae" en r 890 , un año después que Casal se inspirara en el "Nocturno de San Silvestre". Como el "Paz animae" de Casal lleva fecha de octubre de 1890 podemos suponer que éste contesta a las admoni. ciones de Nájera:

Nájera.-No busques contancia en los amores, no pidas nada eterno a los mortales, y haz, artista, con todos tus dolores excelsos monumentos sepulcrales. 


$$
\begin{aligned}
& \text { Casal.- No me habléis de dichas terrenales } \\
& \text { que no ansío gustar. Está ya muerto } \\
& \text { mi corazón, y en su recinto abierto } \\
& \text { sólo entrarán los cuervos sepulcrales. } \\
& \text { Nájera. — En esta vida el único consuelo } \\
& \text { es acordarse de las horas bellas, } \\
& \text { y alzar los ojos para ver el cielo... } \\
& \text { cuando el cielo está azul o tiene estrellas. } \\
& \text { Casal.- - No veo más que un astro oscurecido } \\
& \text { por brumas de crepúsculo lluvioso } \\
& \text { y entre el silencio de sopor profundo, } \\
& \text { tan sólo llega a percibir mi oído } \\
& \text { algo extraño y confuso y misterioso } \\
& \text { que me arrastra muy lejos de este mundo. }
\end{aligned}
$$

Todo parece indicar un diálogo entre los dos poetas, los dos dentro de la misma tradición, los dos condenados a vivir lejos de los grandes centros intelectuales de sus mundos, Paris y Madrid. En septiembre de I89I Casal le dedica a Nájera "El camino de Damasco" que no es la compo. sición parnasiana que se ha querido ver sino que ha sido escrita bajo el signo de Moreau, y posiblemente Nájera, buen conocedor de pintura - lo mismo que su amigo Martí - haya estado en el secreto de la composi. ción. El tema indica que Casal estaba al tanto de la fe religiosa que Nájera logró conservar como un tesoro durante toda su vida. Desgraciadamente Casal no tuvo un Justo Sierra que diera a conocer el valor escondido de sus poemas sino que fue la víctima propiciatoria de unos cuantos cronistas estridentes, más decididos a probar las excentricidades del poeta que el mecanismo de su poesía, como pasó con el venerable Ramón Meza cuyo único derecho a la posteridad es la serie de tonterias que escribió sobre Casal, de quien nunca fue amigo íntimo.

. Las huellas, contaminaciones o inspiración común a los dos poetas son constantes en la poesía de Casal. Naturalmente que estos dos hombres que leian los mismos libros y vivian la misma frustración, no podian menos que presentar muchos puntos de contacto. Coinciden en las fórmulas, Nájera en I877 escribe "Tiene la palidez de la tristeza" en "Juana" y Casạl cinco años más tarde repite en "Nihilismo": "Y mi pálida novia la tristeza". O el Nájera de "Myrthos" dice "Porque siente mi espiritu al mirarte/la frenética fiebre de Abelardo" \& Casal en "Virgen triste" se hace 
eco de uno de los grandes tópicos del siglo XIX: "cual lo sintió Lohengrin delante de Elsa/y al mirar a Eloísa Pedro Abelardo". En una de sus piezas de $\mathrm{r}^{877,}$ "Valleto y $\mathrm{Ca}$ " escribe Nájera:

Eres tú: bien conozco esos hechizos

y ese altivo mirar que me encadena,

la cascada opulenta de tus rizos

$y$ tus hombros ebúrneos de sirena.

Catorce años después Casal repite el tema con una extraña resonancia de rimas en la composición que dedicó a María Cay y que como todas sus obras de album está teñida de cierta nota de afectación. Se trata de "Camafeo" donde parece haber cedido a una petición y no a su espíritu creador:

¿Quién no le rinde culto a tu hermosura

$y$ ante ella de placer no se enajena,

si hay en tu busto lineas de escultura

$y$ hay en tu voz acentos de sirena?

Las semejanzas de forma son bastante superficiales y prueban solamente que dentro de una misma tradición los dos poetas tenian que coincidir en muchas esquinas. Los separa, en cambio, una tremenda escisión espiritual que deja a Casal en su rincón solitario y establece a Nájera más cerca de Dario, a quien hubo de prestar tantos temas. Esta afirmación puede probarse con "Neurosis".

La raíz de "Neurosis" se ha buscado en "La duquesa Job" y en el soneto "De invierno" de Dario. Esta afanosa búsqueda de antecedentes olvida que hay duquesas Job en cualquier ambiente porque las cortesanas y soñadoras son comunes a todas las literaturas y muy especialmente a la vida galante francesa. Si Cora Pearl fue motivo de una crónica de Casal, ¿por qué no habia de ser ella el modelo de Noemi, heroína de "Neurosis" ?16 Amén de que hay muchas diferencias entre la cortesana de Casal y

16 "Memorias de Cora Pearl", El Pais, 7 feb. 1891. Rios de tinta han corrido para documentar el amor al lujo, el preciosismo decorativo y las "chinerías" que caracterizaron las preferencias de Casal. Se trata simplemente de que aceptó la moda de su tiempo como también la aceptó Proust, que nos habla, lo mismo que Casal, de Juana Samary o del decorado rutilante de las casas que recuerda. Casal vivía muy dentro de su tiempo y para lo que nosotros es anacrónico para él fue contemporáneo y de gran estilo, aunque con el presente renacimiento del Art Novedu los gustos de Casal se han reivindicado. Cora Pearl fue una inglesa oriunda de Devon, nacida hacia 1842, que se dedicó en Francia a la prostitución en gran 
las mujeres que inspiran a Nájera y Dario. El espiritu de la "Duquesa Job" se resume en:

\author{
Desde las puertas de la Sorpresa \\ hasta la esquina del Jockey Club, \\ no hay española, yankee o francesa, \\ ni más bonita, ni más traviesa \\ que la duquesa del duque Job.
}

Esta chiquilla de Nájera es feliz y dinámica, capaz de darle un sombrillazo al que la importune. Carolina, su hermana menor-la duquesa es de $x 884$ y la Carolina de Darío de 1890 - es elegante y soñadora. Es una mujer con alma de animal doméstico sin más función que estirarse y sonreír. Tanto en Nájera como en Darío se nota un fondo voluptuoso de amor satisfecho. Es un amor juguetón y ocasional, sin complicaciones sentimentales, una elegante situación donjuanesca de gracia frívola y za. lamera. Nada tiene en común la Noemí de Casal con estas dos mujeres, ni siquiera en la profesión, porque su amor es abiertamente mercenario, es amor de "pálida pecadora":

$$
\begin{aligned}
& \text { Pero ¿qué piensa la hermosa dama? } \\
& \text { ¿es que su príncipe ya no la ama } \\
& \text { como en los dias de amor feliz, } \\
& \text { o que en los cofres del gabinete } \\
& \text { ya no conserva ningún billete } \\
& \text { de los que obtuvo por un desliz? }
\end{aligned}
$$

Casal es lo suficientemente complicado para saber usar la ambigüedad astutamente y "un billete" se presta a las interpretaciones más sutiles. Noemí no es la niña traviesa del poema mexicano ni la indolente ena. morada del Paris que todavía no había visitado Rubén Darío. Tiene una dimensión emocional que no hay en ninguna de sus predecesoras. Lo cautivante en "Neurosis" no es el cuadro luminoso de los guantes, el im-

estilo. Hace gala de sus gabinetes repletos de tesoros, sus grandes fuentes de plata y sus tazones de oro grabado. Sus Memorias, escritas sin humor ni elegancia, son ticas en referencias a sus costosos lujos y no falta un Kahdil Bey en cuyo palacio se entretenía en "bañaderas de mármol tosa, dormía largas horas en divanes perfumados con flores exóticas, conjurando sueños de palacios encantados, † cuando me despertaba la realidad era aún más bella": Era amiga de los amigos de Musset y de Dumas hijo, no faltaba a las representaciones de Sardou, tenía un perrillo "cubano" (posiblemente un maltés) y como era de esperarse murió en la miseria. No sería extraño que fuese esta Cora la cortesana a la que alude Eşa de Queiroz en La reliquia. 
presionismo pictórico del abanico blanco y la sombrilla azul, ni el 'rojo de los biombos, sino el símbolo de la mujer fatal, el espíritu de Dalila, la destructora de hombres, el eterno femenino. La imagen reluciente y externa sirve de contraste al hambre ontológica del ser humano, lo inal. canzable, el tiger, tiger, buming bright de las ansias de Blake. La referencia no es artificiosa porque hay en Casal ecos de la misma desesperación del poeta inglés. Los grandes temas humanos del amor y la muerte son $\tan$ invariables y continuos que se hacen monótonos y no es sorpren. dente que poetas de la misma sensibilidad presenten muchos puntos de contacto. A veces las fórmulas son las mismas. Cuando Blake escribe en "Fair Eleanor": Sickly smells/of deatb issue as from a sepulchre, Casal dice "Acre olor de sepulcros" y la identificación que los dos establecen entre la noche y su tristeza se debe más a coincidencias anímicas que a la tónica del romanticismo. Es inútil explorar la poesía de Casal con los mismos instrumentos críticos que se aplican a la poesia de Darío o a la de Nájera. En su atormentado sentir Casal está más cerca de Blake y de Baudelaire que de las explosiones coruscantes que caracterizaron al modernismo. Casal se mueve en un mundo poético hacia dentro, de esencia-existencia y para la mayor parte de los modernistas el mundo es color-existencia. El énfasis que pusieron sus contemporáneos en subrayar su aislamiento, el desprecio desdeñoso con que los cultivadores del chateo describieron su vida, su trabajo, sus preferencias, no fueron sino la reacción de los adocenados ante el naufragio de un espiritu, la maldición que sufren todos los poetas profundos.

Habria que añadit, una vez más que tanto Casal como Darío, como Nájera, empiezan donde quedaron los romảnticos. Esto ya lo ha demostrado Emilio Carilla y ésta es la actitud crítica que ha rescatado a Víctor Hugo estableciendo una línea continua en la poesía francesa a partir del romanticismo. ${ }^{17}$ Por lo demás se podría afirmar, con cierta crueldad esta. dística y a riesgo de herir mucho patriotismo literario, que tanto Casal como Darío son poetas derivativos y esta cualidad puede extenderse a todo el modernismo con excepción de José Martí, cuya técnica, estilo e imágenes recorren caminos más amplios y menos transitados. En Martí se funden todas las tradiciones, directamente y sin traducción, y se amalgaman con el tesoro de la sabiduría española. Hubiésemos tenido modernismo sin Darío aunque se hubiera demorado unos meses o unos años en alcanzar la contagiosa difusión prestada por la personalidad impetuosa de Rubén, el magnífico, pero si la América española no hubieta

$17 \mathrm{~V}$. Emilio Carilla, El romanticismo en la América bispanica (Madrid, 1958) y Marcel Raymond, From Bandelaite to Surrealism (New York, 1950). 
conocido la bendición de Marti, le habría llevado más de medio siglo el integrar todas las tendencias y aspiraciones que flotaban en la atmósfera espiritual del nuevo mundo. Martí supo dirigir espiritualmente a su América, nuestra América, y canalizar su palabra. De él tomó Darío el tono empenachado y vibrante, los giros atrevidos y el vivir cosmopolita, aun. que nunca llegara a penetrar sus vivencias politicas, su ternura social. Otros aspectos del modernismo, el refinamiento, el gesto novedoso, la evasión elegante, se registran desde los milochocientos en las revistas pol. vorientas y olvidadas de la isla de Cuba. Mientras no se resucite cuida. dosamente todo ese periodismo preferido mucho de lo que sabemos sobre el modernismo no pasará de ser intrascendente juego literatio.

Esperanza Figueroa

Montclair State College 
